\title{
SILP Materials as Effective Catalysts in Selective Monofunctionalization of 1,1,3,3-Tetramethyldisiloxane
}

\author{
Rafal Kukawka 1,2,*(1), Anna Pawlowska-Zygarowicz ${ }^{2,3}$, Rafal Januszewski ${ }^{3,4}$, \\ Joanna Dzialkowska $^{3}\left(\mathbb{D}\right.$, Mariusz Pietrowski $^{3}$, Michal Zielinski $^{3} \mathbb{D}$, Hieronim Maciejewski $^{2,3}{ }^{(D)}$ \\ and Marcin Smiglak 1,2,*(D) \\ 1 Innosil Sp. z o.o., ul. Rubiez 46, 61-612 Poznan, Poland \\ 2 Poznan Science and Technology Park, Adam Mickiewicz University Foundation, ul. Rubiez 46, \\ 61-612 Poznan, Poland; anna.pawlowska@amu.edu.pl (A.P.-Z.); \\ hieronim.maciejewski@ppnt.poznan.pl (H.M.) \\ 3 Faculty of Chemistry, Adam Mickiewicz University, ul. Uniwersytetu Poznańskiego 8, \\ 61-614 Poznan, Poland; r.janusz@amu.edu.pl (R.J.); joadzi5@st.amu.edu.pl (J.D.); mariop@amu.edu.pl (M.P.); \\ mardok@amu.edu.pl (M.Z.) \\ 4 Centre for Advanced Technologies, Adam Mickiewicz University, ul. Uniwersytetu Poznańskiego 10, \\ 61-614 Poznan, Poland \\ * Correspondence: kukawka.rafal@gmail.com (R.K.); marcin.smiglak@gmail.com (M.S.)
}

Received: 20 October 2020; Accepted: 30 November 2020; Published: 3 December 2020

\begin{abstract}
Functionalized siloxanes are one of the most important classes of organosilicon compounds, thus the enhancement of current methods of its synthesis is an important issue. Herein, we present the selective and highly effective reaction between 1,1,3,3-tetramethyldisiloxane (TMDSO) and 1-octene (1-oct), using SILP (supported ionic liquid phase) materials containing a rhodium catalyst immobilized in three phosphonium ionic liquids (ILs) differing in the structure of cation. Studies have shown high potential for using SILP materials as catalysts due to their high catalytic activity and selectivity, easy separation process, and the possibility of reusing the catalyst in subsequent reaction cycles without adding a new portion of the catalyst. Using the most active SILP material $\mathrm{SiO}_{2} /\left[\mathrm{P}_{66614}\right]\left[\mathrm{NTf}_{2}\right] /\left[\left\{\mathrm{Rh}\left(\mu-\mathrm{OSiMe}_{3}\right)(\operatorname{cod})\right\}_{2}\right]$ allows for reuse of the catalyst at least 50 times in an efficient and highly selective monofunctionalization of TMDSO.
\end{abstract}

Keywords: supported ionic liquid phase; ionic liquids; hydrosilylation; heterogeneous catalysis

\section{Introduction}

Functionalized organosilicon compounds, due to their unique properties, have generated much attention in a variety of organic processes [1-3]. Taking into account the importance of these compounds in industry, new methods of synthesis are being sought. One of the most interesting examples of these compounds is 1,1,3,3-tetramethyldisiloxane (TMDSO), which can be used in such applications as preparation of functionalizing agents of fluorinated polyethers [4], polysiloxane ingredients for heat conductible silicone compositions [5], and surfactants for the production of skincare cosmetics [6]. The conventional methods for obtaining unsymmetrical silicon-based compounds involve the condensation reactions and co-hydrolysis reactions of two silanols-chlorosilanes and alkoxysilanes [7]. However, the hydrosilylation reaction seems to be the most convenient procedure for the synthesis of new organosilicon derivatives [8-10]. Although hydrosilylation reactions are widely investigated and performed in homogenous single-phase systems [11-16], there is still the problem of the later separation of the catalyst from the product phase after the reaction [17]. To overcome 
this problem, attempts are being made to develop novel methods for the hydrosilylation reaction performed in heterogeneous systems. One possible solution to this problem is using supported or immobilized catalysts on a solid support. Such prepared catalysts can be easily recovered after the reaction, thus allowing the carrying out of many reaction cycles without an additional portion of catalyst [18]. Another approach widely described in the literature in recent years is to use biphasic reaction systems, where one phase consists of ionic liquid and catalysts dissolved in it and the second phase is formed by a mixture of substrates immiscible with the ionic liquid phase [19].

Reactions carried out in biphasic systems allow for separation of the ionic liquid/catalyst phase and its reuse in the next reaction cycles. However, the mass-transport limitations between phases in reactions carried out in biphasic liquid/liquid systems cause a need to investigate new possibilities for catalyst immobilization using ionic liquids (ILs). Adsorption of ionic liquid (with catalyst dissolved in IL phase) on a highly porous solid support may solve the problem of limited mass transfer [20]. Additionally, the adsorption of IL and the catalyst in the form of a thin layer that adsorbs the solid and highly porous solid supports, such as active carbon, mesoporous materials, or silica [21-24], allows for easy separation of the immobilized catalyst from the reaction mixture and of its reuse in the next reaction cycles, making the process more green and sustainable [22]. Such prepared catalytic systems, known as SILP (supported ionic liquid phase) materials, have found applications in hydrodeoxygenation, hydrogenation, hydrosilylation, the oxidation of alcohols, reforming of cellulose, and others [25-28]. Due to their unique properties, such as high surface area, the high thermal stability of ILs and the support, the polar character of ILs, and thus, the insolubility of ILs in many organic compounds, SILP materials could be successfully used in hydrosilylation reactions as highly efficient, selective, and reusable catalysts [24].

Until now, our group has published the results of using SILP materials with phosphonium ionic liquids as catalysts in hydrosilylation reactions between 1-octene and heptamethyltrisiloxane (HMTS) [24]. The application of SILPs to the performed reactions allowed for significant improvement in our process by decreasing the required amount of catalyst by 10 times, shortening the reaction time from 60 to $30 \mathrm{~min}$, and primarily, extending the number of cycles that can be performed with the same portion of SILP catalyst. On the other hand, we have successfully developed a strategy for high-yield and selective synthesis of monofunctionalized TMDSO derivatives while performing the reaction in a biphasic system, where the catalyst is immobilized in the ionic liquid phase [29]. Moreover, we have found IL/catalyst systems that allow for easy separation of product from the IL/catalyst phase and later for its reuse up to 20 times without the need for adding a new portion of the catalyst.

The main goal of this article was to apply the concept of using efficient SILP materials (composed of a silica support, phosphonium IL, and rhodium catalyst) to obtain monofunctionalized TMDSO derivatives while maintaining easy product separation and reusability of the catalyst. Moreover, the presented approach led to the selective formation of unsymmetrical disiloxane equipped with an n-octyl group as well as the $\mathrm{H}-\mathrm{Si}$ moiety, which can be used in subsequent catalytic transformations.

\section{Results and Discussion}

\subsection{SILP Preparation}

Based on our previous experiments, three ionic liquids were chosen for the study and were to be adsorbed on silica support. Selected salts, namely, tributylmethylphosphonium bis(trifluoromethane)sulfonimide $\left[\mathrm{P}_{4441}\right]\left[\mathrm{NTf}_{2}\right]$, tetraoctylphosphonium bis(trifluoromethane)sulfonimide $\left[\mathrm{P}_{8888}\right]\left[\mathrm{NTf}_{2}\right]$, and trihexyltetradecylphosphonium bis(trifluoromethane)sulfonimide $\left[\mathrm{P}_{66614}\right]\left[\mathrm{NTf}_{2}\right]$ (Figure 1) were chosen due to their (i) proven high thermal stabilities (decomposition temperature is $371-384^{\circ} \mathrm{C}$ ), (ii) long thermal stability (loss of weight of ionic liquid range from 0.17 to $0.40 \%$ at $100{ }^{\circ} \mathrm{C}$ over $10 \mathrm{~h}$ ), (iii) rhodium catalysts immobilized in ionic liquid are very efficient in the hydrosilylation reaction of 1-octene and TMDSO (yield higher than 90\% even after 20 reaction cycles), and (iv) the high catalytic activity when using SILP materials with these ionic liquids (yield higher than $90 \%$ even after 
20 reaction cycles) in the hydrosilylation reaction between 1-octene and HMTS. In comparison to the results published earlier, we decided to not to perform experiments with $\left[\mathrm{P}_{4441}\right]\left[\mathrm{MeSO}_{4}\right]$ due to its instability and lower activity when used in SILP material [24].

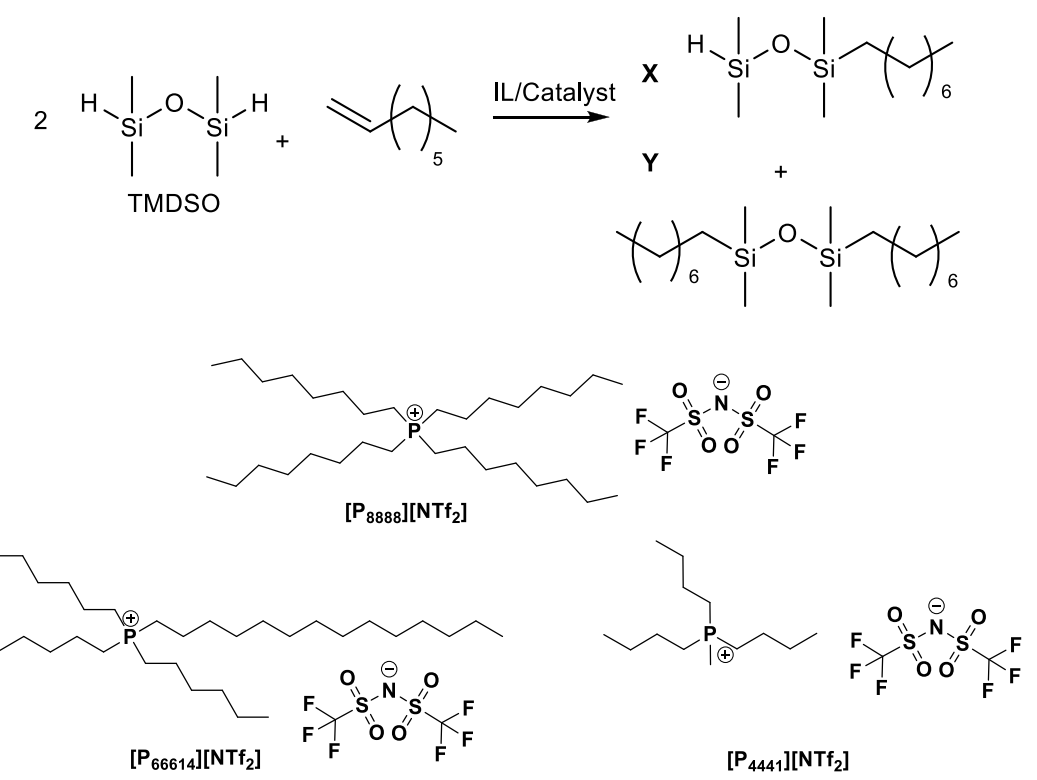

Figure 1. Top: Possible products $(X-$ monofunctionalized; $Y$-bifunctionalized product synthesized in model reaction of 1,1,3,3-tetramethyldisiloxane and 1-octene. Bottom: ILs used in experiments.

Rhodium catalysts used in the experiments (Wilkinson's catalyst $\left[\mathrm{RhCl}\left(\mathrm{PPh}_{3}\right)_{3}\right]$, bis $(\mu-$ trimethylsiloxy)bis(1,5-cyclooctadiene)rhodium(I) $\left[\left\{\mathrm{Rh}\left(\mu-\mathrm{OSiMe}_{3}\right)(\operatorname{cod})\right\}_{2}\right]$, and di( $\mu$-chloro $)$ bis $(1,5-$ cyclooctadiene)dirhodium(I) $\left.\left[\mathrm{Rh}(\mu-\mathrm{Cl}(\operatorname{cod})\}_{2}\right]\right)$ were chosen due to their high catalytic activities reported in the literature [30].

SILP materials were prepared by impregnation of ionic liquid (Table 1) (loaded at 10\% IL (w/w)) and catalyst (to be later used in the experiments at molar ratio TMDSO:1-oct:[Rh]: 2:1:2 $\times 10^{x}$, where $x$ is -5 , -6 , and -7$)$ on calcined silica surface $\left(500^{\circ} \mathrm{C}, 24 \mathrm{~h}\right)$. SILP materials were obtained with three different rhodium concentrations to examine their catalytic activity and the number of cycles over which catalyst is active [24]. The synthesis pathway of SILPs is described in details in the experimental section.

Table 1. Obtained supported ionic liquid phase (SILP) materials loaded at $10 \%$ ionic liquid (IL) (w/w).

\begin{tabular}{ccc}
\hline SILP Material & IL & Complex (Catalyst) \\
\hline (A1) & {$\left[\mathrm{P}_{4441}\right]\left[\mathrm{NTf}_{2}\right]$} & $\left.\left[\mathrm{Rh}_{(\mathrm{PPh}}\right)_{3} \mathrm{Cl}\right]$ \\
(A2) & {$\left[\mathrm{P}_{4441}\right]\left[\mathrm{NTf}_{2}\right]$} & {$\left[\left\{\mathrm{Rh}\left(\mu-\mathrm{OSiMe}_{3}\right)(\mathrm{cod})\right\}_{2}\right]$} \\
(A3) & {$\left[\mathrm{P}_{4441}\right]\left[\mathrm{NTf}_{2}\right]$} & {$[\{\mathrm{Rh}(\mu-\mathrm{Cl})(\mathrm{cod})\}]_{2}$} \\
(B1) & {$\left[\mathrm{P}_{8888}\right]\left[\mathrm{NTf}_{2}\right]$} & {$\left[\mathrm{Rh}(\mathrm{PPh})_{3} \mathrm{Cl}\right]$} \\
(B2) & {$\left[\mathrm{P}_{8888}\right]\left[\mathrm{NTf}_{2}\right]$} & {$\left[\{\mathrm{Rh}(\mu-\mathrm{OSiMe})(\mathrm{cod})\}_{2}\right]$} \\
(B3) & {$\left[\mathrm{P}_{8888}\right]\left[\mathrm{NTf}_{2}\right]$} & {$[\{\mathrm{Rh}(\mu-\mathrm{Cl})(\mathrm{cod})\}]_{2}$} \\
(C1) & {$\left[\mathrm{P}_{66614}\right]\left[\mathrm{NTf}_{2}\right]$} & {$\left[\mathrm{Rh}(\mathrm{PPh})_{3} \mathrm{Cl}\right]$} \\
(C2) & {$\left[\mathrm{P}_{66614}\right]\left[\mathrm{NTf}_{2}\right]$} & {$\left[\left\{\mathrm{Rh}(\mathrm{cod})\left(\mu-\mathrm{SiMe}_{3}\right)\right\}_{2}\right]$} \\
(C3) & {$\left[\mathrm{P}_{66614}\right]\left[\mathrm{NTf}_{2}\right]$} & {$[\{\mathrm{Rh}(\mu-\mathrm{Cl})(\mathrm{cod})\}]_{2}$} \\
\hline
\end{tabular}

\subsection{Textural Properties of SILP Materials}

To characterize the obtained SILP materials and prove the successful adsorption of IL on the silica surface, an experiment of the low-temperature adsorption of nitrogen on the surface, infrared (IR) spectroscopy tests, and scanning electronic microscopy (SEM) were performed. 
Low temperature nitrogen adsorption-desorption tests showed that the silica support after the impregnation of IL exhibited changed surface properties (Table 2). The Brunauer-Emmett-Teller (BET) specific surface area and the total pore volume values were reduced when comparing the SILP material to initial calcined silica from 326.5 to $220.5 \mathrm{~m}^{2} / \mathrm{g}$ (BET surface) and from 1.10 to $0.75 \mathrm{~cm}^{3} / \mathrm{g}$ (total pore volume), as the result of the formation of an IL film within the pores. On the other hand, the mesopores were not completely filled or blocked by the IL layer as the calculated $\alpha$ degree (pore filling degree of support as the ratio of IL volume to support pore volume) was within the range of 0.21 to 0.32 . All obtained low temperature nitrogen adsorption/desorption isotherms belong to Type IVa (according to the International Union of Pure and Applied Chemistry (IUPAC) classification [31]) with a clearly marked hysteresis loop characteristic of mesoporous materials. Average pore diameters for calcined $\mathrm{SiO}_{2}$ and SILP materials are similar (11.0-15.8 nm).

Table 2. BET characterization of calcined silica and SILP materials, pore filling degree $(\alpha)$ and layer thickness.

\begin{tabular}{cccccc}
\hline Sample & $\begin{array}{c}\text { BET Surface } \\
\text { Area }\left[\mathbf{m}^{\mathbf{2}} / \mathbf{g}\right]\end{array}$ & $\begin{array}{c}\text { Total Pore } \\
\text { Volume }\left[\mathbf{c m}^{\mathbf{3}} / \mathbf{g}\right]\end{array}$ & $\begin{array}{c}\text { Average Pore } \\
\text { Diameter [nm] }\end{array}$ & $\boldsymbol{\alpha}^{\mathbf{1}}$ & $\begin{array}{c}\text { Layer Thickness } \\
\mathbf{2}[\mathbf{n m}]\end{array}$ \\
\hline $\mathrm{SiO}_{2}$ calcined & 326.5 & 1.10 & 11.0 & - & - \\
SILP (A1) & 220.5 & 0.88 & 15.8 & 0.21 & 0.67 \\
SILP (B1) & 227.4 & 0.88 & 15.3 & 0.21 & 0.67 \\
SILP (C1) & 251.0 & 0.75 & 11.8 & 0.32 & 1.07 \\
\hline
\end{tabular}

${ }^{1}$ Pore filling degree of support as the ratio IL volume/support pore volume; ${ }^{2}$ the ratio of the IL volume used for coating and the initial surface area.

The absorption of IL on the silica support was proved by comparing the IR spectra of the calcined silica with the spectra of the SILP materials (Figure 2). Characteristic bands referring to IL $\left(2900 \mathrm{~cm}^{-1}\right.$ for P-alkyl bands) were observed in all spectra of the SILP materials and not observed in the case of the spectra of calcined silica.

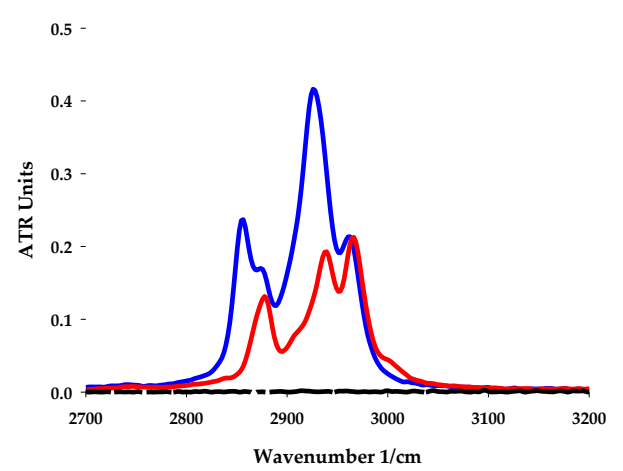

Figure 2. IR spectrum of calcined silica support (black), $\left[\mathrm{P}_{4441}\right]\left[\mathrm{NTf}_{2}\right]$ (blue) and SILP (A1) (red).

To examine the changes in silica surface, SEM analysis of the SILP surface prior to and after impregnation was performed on the example of SILP (A1). The smoother surface of the SILP material, as a consequence of filling pores of silica by a thin layer of IL, is presented in Figure 3. The analysis of SEM images is in agreement with previously described tests and confirms the successful absorption of IL on a silica support. 

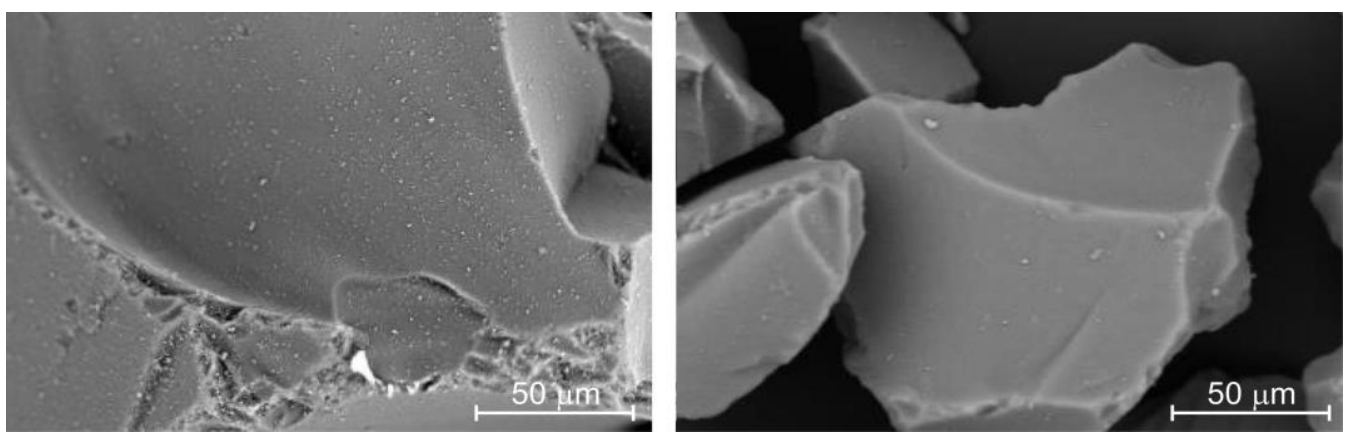

Figure 3. SEM analysis of silica surface (left) and SILP (A1) surface (right) at magnification 585, Acc. Voltage; $15.0 \mathrm{kV}$.

\subsection{Catalytic Activity}

Catalytic activity was determined on the reaction between TMDSO and 1-octene in a molar ratio of 2:1. The reactor was charged with the SILP material in an amount corresponding to a molar ratio of TMDSO:1-oct:[Rh] to 2:1:2 $\times 10^{\mathrm{x}}$, where $\mathrm{x}$ is $-5,-6$, or -7 . The mixture was stirred and heated at $50{ }^{\circ} \mathrm{C}$ for $30 \mathrm{~min}$. Subsequently, the system was cooled to room temperature and the liquid phase was separated from the solid SILP material. The product phase was then analyzed by GC and GC/MS/MS to confirm conversion and selectivity. Then, the SILP material was reused in the next reaction cycle.

In general, the use of all SILP materials at a molar ratio TMDSO:1-oct:[Rh] 2:1:10 ${ }^{-5}$ resulted in obtaining high conversion (99\%) of 1-octene over at least 13 cycles (Table 3). In the case of SILPs (A3), (B3), (C1), (C2), and (C3), 99\% conversion was maintained over 20 cycles tested with given SILP (maximum tested). The tenfold reduction in catalyst concentration (molar ratio TMDSO:1-oct:[Rh] 2:1:2 $\times 10^{-6}$ ) resulted in a decrease in catalytic activity. Only in the case of SILP (A3), conversions above $99 \%$ were maintained to the 14th cycle, and in the case of SILP (C3)-to the 9th cycle. A subsequent tenfold reduction in the catalyst concentration (molar ratio TMDSO:1-oct:[Rh] 2:1:10 ${ }^{-7}$ ) resulted in a drastic decrease in activity. In most cases, only the first cycle with $99 \%$ conversion was achieved and then, a rapid drop in conversion was observed. The influence of the ionic liquid on the catalytic activity is also visible. Always, the largest number of cycles could be carried out when SILP materials contained ionic liquid $\left[\mathrm{P}_{666614}\right]\left[\mathrm{NTf}_{2}\right]$, which is in line with the published data concerning SILP activity in the hydrosilylation reaction between 1-octene and HMTS [24]. When comparing the activity of rhodium catalysts themselves, ([\{Rh( $\left.\mu-\mathrm{Cl})(\operatorname{cod})\}]_{2}\right)$ showed the highest activity of all tested Rh catalysts. The most important advantage of the process, apart from the high catalytic activity in many cycles, is also the high selectivity of the formation of the A product. Selectivity of $95-100 \%$ is observed when using all of the tested SILPs (Tables S1-S3). This is a significant achievement in comparison to reactions carried out in conventional solvents, which allow the product to be obtained with a selectivity of 66:33\% for A:B products [29]. As mentioned earlier, in the case of SILP (A3), (B3), (C1), (C2), and (C3), the $99 \%$ conversion was maintained for the 20 tested cycles. Therefore, in order to test catalytic activity in further cycles, reactions using SILP (C2) were carried out up to 50 cycles. SILP (C2) was used due to its high activity at catalysts concentration of $10^{-5}, 10^{-6}$, and $10^{-7}$. Tests have shown that after 50 reaction cycles, the conversion was still at the level of $99 \%$, with $98 \%$ selectivity. Due to the still high catalytic activity and the absence of symptoms of poisoning and high leaching of the catalyst, subsequent cycles were not performed. Carrying out 50 cycles without a decrease in conversion and the need for adding new portion/regeneration of a catalyst makes SILP (C2) extremely interesting for industrial applications and is the most efficient catalyst we have obtained so far. 
Table 3. Conversion of hydrosilylation reaction using SILP materials.

\begin{tabular}{|c|c|c|c|c|c|c|c|c|c|c|c|c|c|c|c|c|c|c|c|c|c|c|c|c|c|c|c|}
\hline Catalyst & (A1) & (B1) & (C1) & (A2) & (B2) & (C2) & (A3) & (B3) & (C3) & (A1) & (B1) & (C1) & (A2) & (B2) & (C2) & (A3) & (B3) & (C3) & (A1) & (B1) & (C1) & (A2) & (B2) & (C2) & (A3) & (B3) & (C3) \\
\hline Cycle Number & \multicolumn{9}{|c|}{ Molar Ratio TMDSO:1-oct:[Rh] 2:1:2 $\times 10^{-5}$} & \multicolumn{9}{|c|}{ Molar Ratio TMDSO:1-oct:[Rh] 2:1:2 $\times 10^{-6}$} & \multicolumn{9}{|c|}{ Molar Ratio TMDSO:1-oct:[Rh] 2:1:2 × 10-7 } \\
\hline 1 & $>99$ & $>99$ & $>99$ & $>99$ & $>99$ & $>99$ & $>99$ & $>99$ & $>99$ & $>99$ & $>99$ & $>99$ & $>99$ & $>99$ & $>99$ & $>99$ & 79 & $>99$ & $>99$ & 64 & 32 & 26 & 100 & $>99$ & 10 & 12 & 99 \\
\hline 2 & $>99$ & $>99$ & $>99$ & $>99$ & $>99$ & $>99$ & $>99$ & $>99$ & $>99$ & $>99$ & $>99$ & $>99$ & $>99$ & $>99$ & $>99$ & $>99$ & 73 & $>99$ & 62 & 52 & 11 & 0 & 7 & 56 & 0 & 0 & 63 \\
\hline 3 & $>99$ & $>99$ & $>99$ & $>99$ & $>99$ & $>99$ & $>99$ & $>99$ & $>99$ & $>99$ & $>99$ & $>99$ & $>99$ & $>99$ & $>99$ & $>99$ & 77 & $>99$ & 22 & 44 & 3 & & & & & & 28 \\
\hline 4 & $>99$ & $>99$ & $>99$ & $>99$ & $>99$ & $>99$ & $>99$ & $>99$ & $>99$ & $>99$ & 61 & 91 & $>99$ & 95 & $>99$ & $>99$ & 71 & $>99$ & 11 & 9 & & & & & & & 5 \\
\hline 5 & $>99$ & 86 & $>99$ & $>99$ & $>99$ & $>99$ & $>99$ & $>99$ & $>99$ & $>99$ & 84 & 80 & 32 & 81 & $>99$ & $>99$ & 65 & $>99$ & 3 & & & & & & & & \\
\hline 6 & $>99$ & 70 & $>99$ & $>99$ & $>99$ & $>99$ & $>99$ & $>99$ & $>99$ & 79 & 77 & 64 & & 37 & $>99$ & $>99$ & 58 & $>99$ & & & & & & & & & \\
\hline 7 & $>99$ & 68 & $>99$ & $>99$ & $>99$ & $>99$ & $>99$ & $>99$ & $>99$ & 53 & 46 & 48 & & 28 & 53 & $>99$ & 42 & $>99$ & & & & & & & & & \\
\hline 8 & $>99$ & 62 & $>99$ & $>99$ & $>99$ & $>99$ & $>99$ & $>99$ & $>99$ & 28 & 60 & 46 & & 19 & 46 & $>99$ & 34 & $>99$ & & & & & & & & & \\
\hline 9 & $>99$ & 54 & $>99$ & 90 & $>99$ & $>99$ & $>99$ & $>99$ & $>99$ & 15 & 24 & 32 & & 10 & 32 & $>99$ & 23 & 99 & & & & & & & & & \\
\hline 10 & $>99$ & 51 & $>99$ & 85 & $>99$ & $>99$ & $>99$ & $>99$ & $>99$ & & & 58 & & 9 & 24 & $>99$ & 18 & 87 & & & & & & & & & \\
\hline 11 & $>99$ & & $>99$ & 77 & $>99$ & $>99$ & $>99$ & $>99$ & $>99$ & & & & & & & $>99$ & & 55 & & & & & & & & & \\
\hline 12 & $>99$ & & $>99$ & 61 & $>99$ & $>99$ & $>99$ & $>99$ & $>99$ & & & & & & & $>99$ & & 39 & & & & & & & & & \\
\hline 13 & $>99$ & & $>99$ & 52 & $>99$ & $>99$ & $>99$ & $>99$ & $>99$ & & & & & & & $>99$ & & 38 & & & & & & & & & \\
\hline 14 & $>99$ & & $>99$ & 35 & 73 & $>99$ & $>99$ & $>99$ & $>99$ & & & & & & & $>99$ & & 20 & & & & & & & & & \\
\hline 15 & $>99$ & & 98 & 15 & 26 & $>99$ & $>99$ & $>99$ & $>99$ & & & & & & & 87 & & 26 & & & & & & & & & \\
\hline 16 & $>99$ & & 98 & & & $>99$ & $>99$ & $>99$ & $>99$ & & & & & & & 75 & & & & & & & & & & & \\
\hline 17 & 95 & & 98 & & & $>99$ & $>99$ & $>99$ & $>99$ & & & & & & & 65 & & & & & & & & & & & \\
\hline 18 & 82 & & 96 & & & $>99$ & $>99$ & $>99$ & $>99$ & & & & & & & 34 & & & & & & & & & & & \\
\hline 19 & 61 & & 92 & & & $>99$ & $>99$ & $>99$ & $>99$ & & & & & & & & & & & & & & & & & & \\
\hline 20 & 39 & & 90 & & & $>99$ & $>99$ & $>99$ & $>99$ & & & & & & & & & & & & & & & & & & \\
\hline TOF $\left[\mathrm{h}^{-1} \times 10^{3}\right]$ & 3722 & 1574 & 3916 & 2414 & 2772 & 3960 & 3960 & 3960 & 3960 & 1340 & 1496 & 1432 & 856 & 1152 & 1498 & 3294 & 1080 & 2312 & 394 & 536 & 92 & 52 & 214 & 310 & 20 & 24 & 390 \\
\hline
\end{tabular}




\subsection{Nature of Catalyst}

Due to the presence of the ionic liquids and the reducing conditions ensured by the hydrosiloxane in the tested reaction conditions, the rhodium complex could be reduced to metal colloids rhodium [32], which could be a real active species. In previous studies, we performed tests to determine these active species in catalysis using SILP materials [24]. As was determined before hot filtration tests, transmission electron microscopy (TEM) measurements and mercury poisoning tests indicated that the organometallic rhodium complex, rather than metal particles, is the catalytically active species in this reaction. In these studies, we performed only TEM measurements of the SILP material after reaction and in the evaporated product phase. Tests did not show any metal particles in both examined phases.

\subsection{Leaching of IL and Catalyst from SILP Material}

The drop in the catalytic activity of SILP materials can be caused by leaching of the catalyst and ionic liquid/catalyst from the support. This phenomenon is known for liquid phase reactions with SILP materials and particularly problematic in continuous-flow processes, since even slight solubility of IL in the substrate, product, or solvent phase may cause removal of the thin IL film, accompanied by leaching of the catalyst [20]. To confirm the presence of IL on the SILP material after reaction (after the last reaction cycle), IR spectra of SILPs were recorded. In all cases, characteristic bands from ILs were observed, which proves that IL was still present on the support (Figure 4).

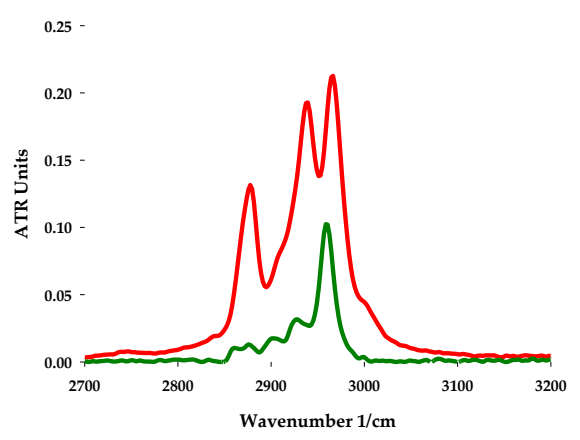

Figure 4. IR spectrum of SILP (A1) before reaction (red) and after the 20th cycle (green).

In order to further determine the leaching of rhodium catalysts into the product phase, inductively coupled plasma (ICP) analysis was conducted. Due to the low limit of detection (1 ppm) [19], the results of ICP analysis were inconclusive and thus, additional experiments were performed as follows: reaction was carried out following the procedure described in Section 3.4 and then, the product phase was separated from the reaction mixture. Subsequently, a new portion of substrates was added to the product phase. Then, the reaction was carried out in $50{ }^{\circ} \mathrm{C}$ over $30 \mathrm{~min}$. Samples of post reaction mixture were collected and analyzed by GC. The experiments were performed only for SILP (B1), as for this reaction system, the yield of the reaction decreases the most significantly with every following reaction cycle and for SILP (C2), as for this SILP, yield of reaction was stable after the 20th cycle. Table 4 presents the conversion of 1-octene after each reaction cycle using SILP (B1) and (C2), and the conversion of 1-octene in post reaction mixtures (with a new portion of substrates added to the product phase, which was separated after each reaction cycle).

Analysis of the data presented in columns II and IV (Table 4) shows that after adding a new portion of substrates to the separated product phase, conversion of the $\mathrm{Si}-\mathrm{H}$ bond is still observed (in the range of $4-10 \%$ ). It is concluded that the rhodium catalyst was presented in the product phase, separated after the first and subsequent reaction cycles, which means that the catalyst had been slightly washed out from the SILP material. In the case of SILP (C2), where the conversion is still observed even after 50 cycles, catalyst leaching is constant, but occurs in a small amount ( $6 \%$ substrate conversion is observed). In the case of SILP (B2), where the conversion drops sharply after several cycles, it can 
be concluded that the decrease in activity results more from poisoning of the catalyst than from its leaching from SILP material to the product phase.

Table 4. Conversion of 1-octene obtained with reaction system containing SILP (B1) and (C2). I: Conversion using SILP (B1). II: Conversion after adding new portion of substrate to product phase (after separation from SILP (B1)). III: Conversion using SILP (C2). IV: Conversion after adding new portion of substrate to product phase (after separation from SILP (C2)).

\begin{tabular}{ccccc}
\hline Cycle Number & $\begin{array}{c}\text { I } \\
\text { SILP (B1) }\end{array}$ & $\begin{array}{c}\text { II } \\
\text { SILP (B1) }\end{array}$ & $\begin{array}{c}\text { III } \\
\text { SILP (C2) }\end{array}$ & $\begin{array}{c}\text { IV } \\
\text { SILP (C2) }\end{array}$ \\
\hline 1 & $>99$ & 7 & $>99$ & 10 \\
2 & $>99$ & 6 & $>99$ & 10 \\
3 & $>99$ & 6 & $>99$ & 9 \\
4 & $>99$ & 4 & $>99$ & 7 \\
5 & 86 & 6 & $>99$ & 6 \\
10 & - & 7 & $>99$ & 7 \\
20 & - & - & $>99$ & 6 \\
30 & - & - & $>99$ & 7 \\
40 & - & - & $>99$ & 6 \\
50 & - & - & & 6 \\
\hline
\end{tabular}

\subsection{Comparison of TOF}

Overall, the high catalytic activity of used SILPs is confirmed by high TOF (turnover frequency) values calculated as amounts of the products expressed in moles obtained in all runs in terms of the initial catalyst used (in moles).

TOF values were compared (Table 5) with the use of two similar catalytic systems containing an ionic liquid: $\left[\mathrm{P}_{66614}\right]\left[\mathrm{NTf}_{2}\right]$ or $\left[\mathrm{P}_{8888}\right]\left[\mathrm{NTf}_{2}\right]$ and the $[\{\mathrm{Rh}(\mu-\mathrm{Cl})(\mathrm{cod})\}]_{2}$ catalyst, when using (i) catalyst dissolved in IL and (ii) catalyst dissolved in IL absorbed on the silica surface (SILP material). The reaction carried out with the use of SILP achieves higher TOF values due to the $99 \%$ activity over 20 reaction cycles and the use of a lower catalyst concentration $\left(10^{-5} \mathrm{vs} .10^{-4}\right.$ in the case of the $\mathrm{IL} /$ catalyst system). In addition, in the case of the reaction in which the SILP catalyst was used, the reaction did not lead to a decrease in conversion, which —in the example of SILP (C2)—shows that the TOF value can be even several times higher. Moreover, comparison of TOF values of the catalytic system without ionic liquid and SILP (catalyst added to mixture of substrates) was performed. TOF values, when assuming the same concentration of catalyst, are significantly lower than when using biphasic IL/catalyst system or SILP systems due to the fact that the reaction can be carried out only in a single cycle (without the possibility of reusing the catalyst). This comparison shows the advantages of using SILP catalyst systems in comparison to the catalytic system without ionic liquids and the improvement over the catalytic system using the catalyst dissolved in ionic liquids.

Table 5. Comparison of TOF $\left[\mathrm{h}^{-1} \times 10^{3}\right]$ without using and with using ILs as solvent for catalyst $[\{\mathrm{Rh}(\mu-\mathrm{Cl})(\mathrm{cod})\}]_{2}$ in the biphasic system and supported on silica (SILP materials).

\begin{tabular}{cccc}
\hline $\begin{array}{c}\text { TMDSO:1-oct:[Rh] } \\
\text { (Reactants/Catalyst Concentration) }\end{array}$ & IL & SILP System & TOF \\
\hline $2: 1: 2 \times 10^{-4}$ & - & - & $20^{1,4}$ \\
$2: 1: 2 \times 10^{-5}$ & - & - & $1928^{2,4}$ \\
$2: 1: 2 \times 10^{-4}$ & {$\left[\mathrm{P}_{8888}\right]\left[\mathrm{NTf}_{2}\right]$} & - & $169^{1,4}$ \\
$2: 1: 2 \times 10^{-4}$ & {$\left[\mathrm{P}_{66614}\right]\left[\mathrm{NTf}_{2}\right]$} & - & $375^{1,4}$ \\
$2: 1: 2 \times 10^{-5}$ & {$\left[\mathrm{P}_{8888}\right]\left[\mathrm{NTf}_{2}\right]$} & $\mathbf{( B 3 )}$ & $3960^{2,3}$ \\
$2: 1: 2 \times 10^{-5}$ & {$\left[\mathrm{P}_{66614}\right]\left[\mathrm{NTf}_{2}\right]$} & $\mathbf{( C 3 )}$ & $3960^{2,3}$ \\
\hline
\end{tabular}

\footnotetext{
${ }^{1} \mathrm{t}=30 \mathrm{~min}$, molar ratio TMDSO:1-oct:[Rh]:2:1:2 $\times 10^{-4} ;^{2} \mathrm{t}=30 \mathrm{~min}$, molar ratio TMDSO:1-oct:[Rh]:2:1:2 $\times 10^{-5}$;

${ }^{3}$ catalytic system is still active after the 20 reaction cycles and more cycles could be performed; ${ }^{4}$ TOF values calculated based on results published before [24,29].
} 


\section{Materials and Methods}

\subsection{Synthesis of Ionic Liquids}

ILs: $\quad$ tributylmethylphosphonium bis(trifluoro-methylsulphonyl)imide $\left[\mathrm{P}_{4441}\right]\left[\mathrm{NTf}_{2}\right]$, tetraoctylphosphonium bis(trifluoro-methylsulphonyl)imide $\left[\mathrm{P}_{8888}\right]\left[\mathrm{NTf}_{2}\right]$, trihexyltetrabutylphosphonium bis(trifluoromethylsulfonyl)imide $\left[\mathrm{P}_{66614}\right]\left[\mathrm{NTf}_{2}\right]$ were synthesized by metathesis reaction from their halogen precursors as was described in the literature [33,34]. Purity of ILs was confirmed by ${ }^{1} \mathrm{H}$ NMR analysis (see ${ }^{1} \mathrm{HNMR}$ data, ESI) and IC analysis (absence of halogen ion was observed, see Figure S1). Tributylmethylphosphonium chloride $\left[\mathrm{P}_{4441}\right][\mathrm{Cl}]$, tetraoctylphosphonium chloride $\left[\mathrm{P}_{8888}\right][\mathrm{Cl}]$, and trihexyltetradecyl phosphonium chloride $\left[\mathrm{P}_{66614}\right][\mathrm{Cl}]$ were purchased from Iolitec.

\subsection{Synthesis of Catalysts}

$\left[\mathrm{Rh}\left(\mathrm{PPh}_{3}\right)_{3} \mathrm{Cl}\right]$ and $[\{\mathrm{Rh}(\mu-\mathrm{Cl})(\mathrm{cod})\}]_{2}$ were purchased from Sigma Aldrich. $\left[\left\{\mathrm{Rh}\left(\mu-\mathrm{OSiMe}_{3}\right)(\mathrm{cod})\right\}_{2}\right]$ was prepared as described by Marciniec et. al. [35].

\subsection{Preparation of SILP Materials}

The silica support before impregnation was calcined $\left(500^{\circ} \mathrm{C}, 24 \mathrm{~h}\right)$ to decrease the number of hydroxyl groups on the silica support. In order to prepare supported ionic liquid on silica with the rhodium catalyst, ionic liquid $(0.2 \mathrm{~g})$ was dissolved in $20 \mathrm{~cm}^{3}$ dichloromethane. Subsequently, $10 \mathrm{~cm}^{3}$ (to be later used in experiments at molar ratio TMDSO:1-oct:[Rh] 2:1:2 $\times 10^{-5}$ ), $1 \mathrm{~cm}^{3}$ (to be later used in experiments at molar ratio TMDSO:1-oct:[Rh] 2:1:2 $\times 10^{-6}$ ), or $0.1 \mathrm{~cm}^{3}$ (to be later used in experiments at molar ratio TMDSO:1-oct: [Rh] 2:1:2 $\left.\times 10^{-7}\right)$ of solution of rhodium catalyst $\left(\left(\left[\mathrm{Rh}\left(\mathrm{PPh}_{3}\right)_{3} \mathrm{Cl}\right]-0.68\right.\right.$ $\mathrm{mg}$, $\left[\{\mathrm{Rh}(\mu-\mathrm{Cl})(\mathrm{cod})\}_{2}-0.18 \mathrm{mg}\right.$, and $\left.\left[\left\{\mathrm{Rh}\left(\mu-\mathrm{OSiMe}_{3}\right)(\mathrm{cod})\right\}_{2}\right]-0.53 \mathrm{mg}\right)$, dissolved in $10 \mathrm{~cm}^{3}$ of dichloromethane) and mesoporous silica (high-purity grade Davisil Grade 62, pore size $150 \AA$, 60-200 mesh, $1.15 \mathrm{~cm}^{3} / \mathrm{g}$ pore volume) $(1.8 \mathrm{~g})$ were added to a solution of IL in dichloromethane. In the next step, the solution was stirred for $30 \mathrm{~min}$ at room temperature and after that, the volatile solvent was very slowly evaporated, leaving a thin ionic liquid film on the surface of the support material. Then, SILP materials were dried under high vacuum at $40{ }^{\circ} \mathrm{C}(48 \mathrm{~h})$.

\subsection{Reactions Using SILP Catalysts}

The reaction system was composed of a glass reactor of $2 \mathrm{~cm}^{3}$ capacity and a side neck for substrate introduction, equipped with a magnetic stirrer and reflux condenser. The reactor was charged with $0.1 \mathrm{~g}$ of SILP material (in $0.1 \mathrm{~g}$ of SILP material is the amount of catalyst corresponding to $4.6 \times 10^{-5}$ mole of Rh (or $10^{-6}$ or $\left.10^{-7}\right)$ ) and then, the substrates $4.6 \mathrm{mmol}(0.62 \mathrm{~g})$ of TMDSO and $2.3 \mathrm{mmol}(0.26$ g) of 1-octene (molar ratio of TMDSO:1-oct:[Rh] 2:1:2 $\times 10^{\mathrm{x}}$, where $\mathrm{x}$ is $-5,-6$ or -7 ) were added). Then, the entire mixture was stirred and heated at $50{ }^{\circ} \mathrm{C}$ for $30 \mathrm{~min}$. Subsequently, the system was cooled to room temperature and the liquid phase was separated from the solid SILP material. The product phase was then analyzed by GC and GC/MS/MS to confirm selectivity and determine conversion and SILP material was reused in the next reaction cycle

\section{5. ${ }^{1} H$ NMR Spectra}

${ }^{1}$ H NMR spectra were recorded on a Varian XL 300 NMR (300 MHz) (Varian, Palo Alto, CA, USA) using $\mathrm{d}_{6}$-DMSO as solvent with tetramethylsilane as the internal standard. Proton chemical shifts (available in the ESI file) are shown in parts per million ( $\delta \mathrm{ppm})$.

\subsection{FT-IR Spectra}

FT-IR spectra were recorded in a Bruker Tensor 27 apparatus (Bruker Corporation Optik GmbH, Bremen, Germany) in the range 500-4000 1/cm of wave number. Solid samples (ca. $1 \mathrm{mg}$ ) were placed 
on a diamond window and then, covered with a sapphire tip. Using OPUS 5.5 software, baseline and peak picking were carried out in order to determine the main peaks in the product.

\subsection{Determination of Surface Area, Pore Volume, and Pore Diameter}

The Brunauer-Emmett-Teller (BET) surface areas were determined by $\mathrm{N}_{2}$ adsorption at $77 \mathrm{~K}$ using a Micromeritics ASAP 2010 sorptometer (Micromeritics Instrument Corp., Norcross, GA, USA). Total pore volume and average pore diameter were determined by applying the Barrett-Joyner-Halenda (BJH) method to the isotherm desorption branch. Prior to the measurements of adsorption/desorption isotherms, the samples were outgassed at $393 \mathrm{~K}$ for $20 \mathrm{~h}$.

\subsection{GC, GC/MS/MS Analysis}

The conversion and selectivity of the reactions were analyzed using a Varian CP 3800 Gas Chromatograph (Varian, Santa Clara, CA, USA) with a FactorFour VF- $5 \mathrm{~ms}$ column $(15 \mathrm{~m} \times 0.25 \mathrm{~mm})$ with decane as internal standard. Additional experiments to confirm the selectivity of the reactions were performed using a Varian 400 GC/MS/MS (Varian, Santa Clara, CA, USA) instrument with a FactorFour VF-1ms column $(15 \mathrm{~m} \times 0.25 \mathrm{~mm})$.

\section{Conclusions}

Based on previous research on the use of SILP materials in the hydrosilylation reaction and the use of ionic liquids in the selective monofunctionalization of TMDSO, it was decided to combine both concepts and apply SILP catalysts to obtain a monofunctionalized derivative of TMDSO. In general, nine SILP materials (differing in structure of cation in IL, rhodium catalyst, and its concentration in SILP material) with three different Rh concentrations were obtained and characterized by the BET, IR, and SEM methods and later used in the hydrosilylation reaction between TMDSO and 1-octene.

The obtained materials, in particular, turned out to be very efficient catalysts, and the most efficient of them (SILP (C2) composed of $\left.\left[\mathrm{P}_{66614}\right]\left[\mathrm{NTf}_{2}\right] /\left[\left\{\mathrm{Rh}\left(\mu-\mathrm{OSiMe}_{3}\right)(\mathrm{cod})\right\}_{2}\right]\right)$ allowed us to obtain 50 reaction cycles with $99 \%$ conversion and $98 \%$ selectivity. Additional studies have shown that the rhodium complexes are slowly leached out of SILP materials; however, leaching does not have a decisive influence on the activity of the SILP material. Certainly, the use of SILP materials in catalysis will contribute to the reduction of energy used during the production process, will contribute to a better use of materials, and will allow for a reduction in the amount of post reaction waste.

Supplementary Materials: The following are available online at http://www.mdpi.com/2073-4344/10/12/1414/s1, ${ }^{1}$ H NMR data for obtained ionic liquids; IC analysis of Ionic Liquids; GC/MS/MS chromatogram and analysis; Figure S1. IC chromatograms of synthesized ILs with $\left[\mathrm{NTf}_{2}\right]^{-}$anion from their chloride precursors. No peak observance at $\sim 4.9$ min means that $[\mathrm{Cl}]^{-}$content in ionic liquid is below limit of detection; Figure S2. GC chromatogram of post reaction mixture obtained from reaction using SILP (A1) after 1st reaction cycle; retention times 0.9 minacetone, 1.5-2.0 min—substrates (1-octene, TMDSO), 6.7 min—decane (internal standard), $10.1 \mathrm{~min}$-product A (octylotetramethyldisiloxane), Figure S3. GC chromatogram of post reaction mixture obtained from reaction using SILP (B1) after 1st reaction cycle; retention times 0.9 min-acetone, 1.5-2.0 min-substrates (1-octene, TMDSO), $6.7 \mathrm{~min}$-decane (internal standard), $10.1 \mathrm{~min}$ - product A (octylotetramethyldisiloxane), Figure S4. GC chromatogram of post reaction mixture obtained from reaction using SILP (C1) after 1st reaction cycle; retention times $0.9 \mathrm{~min}$-acetone, 1.5-2.0 $\mathrm{min}$-substrates (1-octene, TMDSO), $6.7 \mathrm{~min}$-decane (internal standard), $10.1 \mathrm{~min}$ - product A (octylotetramethyldisiloxane), Figure S5. Example of GC chromatogram of post reaction mixture obtained from reaction using SILP (C1) after 4st reaction cycle; retention times 0.9 min-acetone, 1.5-2.0 min-substrates (1-octene, TMDSO), $6.7 \mathrm{~min}$-decane (internal standard), $10.1 \mathrm{~min}$-product A (octylotetramethyldisiloxane), 14.7 min-product B (1,3-dioctylo-1,1,3,3-tetramethyldisiloxane), Figure S6. GC-MS mass spectrum of octylotetramethyldisiloxane obtained from reaction using SILP (A1) recorded at retention time $8.842 \mathrm{~min}$., Table S1. Conversion and selectivity of hydrosilylation reaction using SILP materials $\left(\left[\mathrm{RhCl}_{(}\left(\mathrm{PPh}_{3}\right)_{3}\right]\right)$, Table S2. Conversion and selectivity of hydrosilylation reaction using SILP materials $\left.\left(\left[\left\{\mathrm{Rh}_{(\mu-\mathrm{OSiMe}}\right)(\operatorname{cod})\right\}_{2}\right]\right)$, Table S3. Conversion and selectivity of hydrosilylation reaction using SILP materials $[\{\mathrm{Rh}(\mu-\mathrm{Cl})(\operatorname{cod})\}]_{2}$.

Author Contributions: Conceptualization, H.M., M.S., R.K. and A.P.-Z.; methodology, R.K. and A.P.-Z.; synthesis of ILs, A.P.-Z.; analysis of purity of ILs, R.K., A.P.-Z. and J.D.; synthesis of catalysts, R.J.; synthesis of SILP materials, A.P.-Z.; IR analysis of SILP materials, R.K.; SEM analysis of SILP materials, R.K.; textural analysis of SILP materials, M.P. and M.Z.; catalysis with using SILP materials, A.P.-Z., J.D. and R.K.; GC, GC/MS analysis, R.K. and A.P.-Z.; 
HNMR analysis, R.K.; examination of nature of catalyst, R.K.; leaching studies, R.K.; writing—original draft preparation, R.K.; writing-review and editing, R.K., M.S., R.J., A.P.-Z., M.P. and H.M.; supervision, H.M. and M.S.; project administration, M.S.; funding acquisition, M.S. All authors have read and agreed to the published version of the manuscript.

Funding: M.S. greatly acknowledges funding from the National Science Centre (Poland), project SONATA BIS; grant number UMO-2017/26/E/ST8/01059.

Conflicts of Interest: The authors declare no conflict of interest

\section{References}

1. Lee, V.Y. (Ed.) Organosilicon Compounds. Theory and Experiment (Synthesis); Elsevier: London, UK, 2017. [CrossRef]

2. Januszewski, R.; Kownacki, I.; Maciejewski, H.; Marciniec, B.; Szymańska, A. An Efficient Catalytic Route for the Synthesis of Silane Coupling Agents Based on the 1,1,3,3-Tetramethyldisiloxane Core. Eur. J. Inorg. Chem. 2017, 2017, 851-856. [CrossRef]

3. Hiyama, T.; Shirakawa, E. Organosilicon Compounds. Chemin 2003, 34, 169-218. [CrossRef]

4. Yamane, Y.; Koike, N.; Yamaguchi, K.; Kishita, H. Fluorine-Containing Organopolysiloxane, a Surface Treatment Composition Comprising the Same and an Article Treated with the Composition. European Patent EP1813640B1, 24 February 2010.

5. Sakurai, I.; Matsumoto, N.; Miyoshi, K.; Yamada, K. Heat-Conductive Silicone Composition and Cured Product Thereof. U.S. Patent US8119758B2, 21 February 2012.

6. Leatherman, M.D.; Policello, G.A.; Rajaraman, K. Extreme Environment Surfactant Compositions Comprising Hydrolysis Resistant Organomodified Disiloxane Surfactants. U.S. Patent US7645720B2, 12 January 2010.

7. Brook, M.A. Silicon in Organic, Organometallic and Polymer Chemistry; Wiley-VCH: Weinheim, Germany, 2000.

8. Marciniec, B.; Maciejewski, H.; Pietraszuk, C.; Pawluć, P. Hydrosilylation. A Comprehensive Review on Recent Advances; Springer: Dordrecht, The Netherlands, 2009. [CrossRef]

9. Troegel, D.; Stohrer, J. Recent advances and actual challenges in late transition metal catalyzed hydrosilylation of olefins from an industrial point of view. Co-Ord. Chem. Rev. 2011, 255, 1440-1459. [CrossRef]

10. Marciniec, B.; Maciejewski, H.; Pietraszuk, C.; Pawluc, P. Applied Homogeneous Catalysis with Organometallic Compounds; Cornils, B., Hermmann, W.A., Belier, M., Pawelo, R., Eds.; Wiley-VCH: Weinheim, Germany, 2017; pp. 569-620. [CrossRef]

11. Zhao, Z.-Y.; Nie, Y.-X.; Tang, R.-H.; Yin, G.-W.; Cao, J.; Xu, Z.; Cui, Y.-M.; Zheng, Z.-J.; Xu, L.-W. Enantioselective Rhodium-Catalyzed Desymmetric Hydrosilylation of Cyclopropenes. ACS Catal. 2019, 9, 9110-9116. [CrossRef]

12. Wen, H.; Wang, K.; Zhang, Y.; Liu, G.; Huang, Z. Cobalt-Catalyzed Regio- and Enantioselective Markovnikov 1,2-Hydrosilylation of Conjugated Dienes. ACS Catal. 2019, 9, 1612-1618. [CrossRef]

13. Schuhknecht, D.; Spaniol, T.P.; Maron, L.; Okuda, J. Regioselective Hydrosilylation of Olefins Catalyzed by a Molecular Calcium Hydride Cation. Angew. Chem. Int. Ed. 2020, 59, 310-314. [CrossRef]

14. Raya-Barón, Á.; Oña-Burgos, P.; Fernández, I. Iron-Catalyzed Homogeneous Hydrosilylation of Ketones and Aldehydes: Advances and Mechanistic Perspective. ACS Catal. 2019, 9, 5400-5417. [CrossRef]

15. Jankowska-Wajda, M.; Bartlewicz, O.; Pietras, P.; Maciejewski, H. Piperidinium and Pyrrolidinium Ionic Liquids as Precursors in the Synthesis of New Platinum Catalysts for Hydrosilylation. Catalysts 2020, 10, 919. [CrossRef]

16. Wu, C.; Peng, J.; Li, J.; Bai, Y.; Hu, Y.; Lai, G. Synthesis of poly(ethylene glycol) (PEG) functionalized ionic liquids and the application to hydrosilylation. Catal. Commun. 2008, 10, 248-250. [CrossRef]

17. Pawlowska-Zygarowicz, A.; Kukawka, R.; Maciejewski, H.; Smiglak, M. Optimization and intensification of hydrosilylation reactions using a microreactor system. New J. Chem. 2018, 42. [CrossRef]

18. Cano, R.; Yus, M.; Ramón, D.J. Impregnated Platinum on Magnetite as an Efficient, Fast, and Recyclable Catalyst for the Hydrosilylation of Alkynes. ACS Catal. 2012, 2, 1070-1078. [CrossRef]

19. Jankowska-Wajda, M.; Kukawka, R.; Smiglak, M.; Maciejewski, H. The effect of the catalyst and the type of ionic liquid on the hydrosilylation process under batch and continuous reaction conditions. New J. Chem. 2018, 42, 5229-5236. [CrossRef] 
20. Fehrmann, R.; Riisager, A.; Haumann, M. (Eds.) Supported Ionic Liquids: Fundamentals and Applications; Wiley-VCH: Weinheim, Germany, 2014. [CrossRef]

21. Van Doorslaer, C.; Wahlen, J.; Mertens, P.; Binnemans, K.; De Vos, D. Immobilization of molecular catalysts in supported ionic liquid phases. Dalton Trans. 2010, 39, 8377-8390. [CrossRef] [PubMed]

22. Riisager, A.; Fehrmann, R.; Haumann, M.; Wasserscheid, P. Supported Ionic Liquid Phase (SILP) Catalysis: An Innovative Concept for Homogeneous Catalysis in Continuous Fixed-Bed Reactors. Eur. J. Inorg. Chem. 2006, 2006, 695-706. [CrossRef]

23. Sowińska, A.; Maciejewska, M.; Guo, L.; Delebecq, E. Effect of SILPs on the Vulcanization and Properties of Ethylene-Propylene-Diene Elastomer. Polymers 2020, 12, 1220. [CrossRef] [PubMed]

24. Kukawka, R.; Pawlowska-Zygarowicz, A.; Dzialkowska, J.; Pietrowski, M.; Maciejewski, H.; Bica, K.; Smiglak, M. Highly Effective Supported Ionic Liquid-Phase (SILP) Catalysts: Characterization and Application to the Hydrosilylation Reaction. ACS Sustain. Chem. Eng. 2019, 7, 4699-4706. [CrossRef]

25. Geier, D.; Schmitz, P.; Walkowiak, J.; Leitner, W.; Franciò, G. Continuous Flow Asymmetric Hydrogenation with Supported Ionic Liquid Phase Catalysts Using Modified $\mathrm{CO}_{2}$ as the Mobile Phase: From Model Substrate to an Active Pharmaceutical Ingredient. ACS Catal. 2018, 8, 3297-3303. [CrossRef]

26. Giacalone, F.; Gruttadauria, M. Covalently Supported Ionic Liquid Phases: An Advanced Class of Recyclable Catalytic Systems. Chem CatChem 2016, 8, 664-684. [CrossRef]

27. Kudo, S.; Goto, N.; Sperry, J.; Norinaga, K.; Hayashi, J.-I. Production of Levoglucosenone and Dihydrolevoglucosenone by Catalytic Reforming of Volatiles from Cellulose Pyrolysis Using Supported Ionic Liquid Phase. ACS Sustain. Chem. Eng. 2017, 5, 1132-1140. [CrossRef]

28. Bartlewicz, O.; Dąbek, I.; Szymańska, A.; Maciejewski, H. Heterogeneous Catalysis with the Participation of Ionic Liquids. Catalysts 2020, 10, 1227. [CrossRef]

29. Kukawka, R.; Januszewski, R.; Kownacki, I.; Smiglak, M.; Maciejewski, H. An efficient method for synthesizing monofunctionalized derivatives of 1,1,3,3-tetramethyldisiloxane in ionic liquids as recoverable solvents for rhodium catalyst. Catal. Commun. 2018, 108, 59-63. [CrossRef]

30. Maciejewski, H.; Wawrzynczak, A.; Dutkiewicz, M.; Fiedorow, R. Silicone waxes—synthesis via hydrosilylation in homo- and heterogeneous systems. J. Mol. Catal. A Chem. 2006, 257, 141-148. [CrossRef]

31. Thommes, M.; Kaneko, K.; Neimark, A.V.; Olivier, J.P.; Rodriguez-Reinoso, F.; Rouquerol, J.; Sing, K.S. Physisorption of gases, with special reference to the evaluation of surface area and pore size distribution (IUPAC Technical Report). Pure Appl. Chem. 2015, 87, 1051-1069. [CrossRef]

32. Lewis, L.N.; Uriarte, R.J. Hydrosilylation catalyzed by metal colloids: A relative activity study. Organometallics 1990, 9, 621-625. [CrossRef]

33. Wasserscheid, P.; Welton, T. (Eds.) Ionic Liquids in Synthesis; Wiley-VCH: Weinheim, Germany, 2008. [CrossRef]

34. Zieliński, W.; Kukawka, R.; Maciejewski, H.; Smiglak, M. Ionic Liquids as Solvents for Rhodium and Platinum Catalysts Used in Hydrosilylation Reaction. Molecules 2016, 21, 1115. [CrossRef]

35. Marciniec, B.; Krzyżanowski, P. Synthesis, characterization and some reactions of [(diene) $\operatorname{Rh}(\mu-\mathrm{OSiMe})] 2$. J. Organomet. Chem. 1995, 493, 261-266. [CrossRef]

Publisher's Note: MDPI stays neutral with regard to jurisdictional claims in published maps and institutional affiliations.

(C) 2020 by the authors. Licensee MDPI, Basel, Switzerland. This article is an open access article distributed under the terms and conditions of the Creative Commons Attribution (CC BY) license (http://creativecommons.org/licenses/by/4.0/). 